\title{
Determination of the Radiation Hazard Indices and Excess Lifetime Cancer Risk in Iraqi Bentonite
}

\author{
Rasha S. Ahmed ${ }^{1 *}$, Raghad. S. Mohammed ${ }^{2}$, and Ahlam Rashid Kharbat ${ }^{3}$ \\ ${ }^{1}$ Department of Physiology and Medical Physics, College of Medicine, Al-Nahrain University, \\ Baghdad-Iraq. \\ ${ }^{2}$ Department of Physics, College of Science, Al-Mustansiriyah University, Baghdad-Iraq. \\ ${ }^{3}$ Ministry of Science and Technology, Iraqi National Monitoring Authority, Baghdad-Iraq. \\ * Corresponding Author: rasha.sabeeh.ahmed@colmed-alnahrain.edu.iq. \\ rasha_ryadh@yahoo.com.
}

\begin{abstract}
The activity concentrations for ${ }^{232} \mathrm{Th},{ }^{238} \mathrm{U},{ }^{40} \mathrm{~K}$, and ${ }^{137} \mathrm{Cs}$ were measured in bentonite samples using high purity germanium detector. These samples were collected from the main distribution markets in Baghdad, the capital of Iraq. The mean activity concentrations for ${ }^{232} \mathrm{Th},{ }^{238} \mathrm{U},{ }^{40} \mathrm{~K}$ and ${ }^{137} \mathrm{Cs}$ were found to be $6.10,5.89,162$ and $1.8 \mathrm{~Bq} / \mathrm{kg}$ respectively. The results of specific activities were less than the recommended global values by (UNSCEAR, 2000). The radiation hazard indices in therapeutic bentonite have been also measured. The total air absorbed dose rate, the annual effective dose, the radium equivalent activity, the external hazard index and the excess lifetime cancer risk have a mean value of $13.2 \mathrm{nGy} / \mathrm{h}, 0.0000162 \mathrm{~Sv}, 27 \mathrm{~Bq} / \mathrm{kg}, 0.073$, and 0.000053 respectively. Low radiation hazard indices were recorded. These low levels indicated that the mud is safe, and suitable to be used in therapy, also the dealer with this mud are not exposed to any radiation hazards. [DOI: $10.22401 / \mathrm{JUNS} .21 .1 .09]$
\end{abstract}

Keywords: Bentonite, Radiation hazard, specific activity, high purity germanium detector.

\section{Introduction}

Bentonite is a crag created of extremely colloidal and plastic muds composed generally of montmorillonite and is made by volcanic ash [1].

The transition of ash to bentonite clearly happened only in water during or after deposition [2,3]. Bentonite may include cristobalite, crystalline quartz and feldspar. The specific feature of bentonite is its capability to formulate gels when combined with water and soak up high amount of water with increase in volume of 10-15 times its dry bulk feels greasy to the touch like soap. Difference in commutable cations in the earth's interlayer areas and interstitial water will affect the properties of bentonite, and thus the mercantile uses of the different types of bentonite [4].

Bentonite has a wide uses especially in medicine and paints as well as a stabilizer. In addition, Bentonite used frequently in the treatment of hair and skin rashes, especially in children by mixing the mud with an amount of water and placed on the rushes till it become dry. People who have direct deal with bentonite mud may expose to naturally occurring radionuclides radiation risks [4].

Naturally occurring radionuclides involve all radioactive elements found in the environment, in atmosphere and earth's crust (air, water, and soil) such as uranium, thorium with their products (radium, radon) and potassium.

About $80 \%$ of the whole radiation amount that an individual may be exposed is from background gamma radiation which is $2.4 \mathrm{mSv}$ per person [5]. Assessing the activity concentration of radionuclides in mud is one of the important ways to estimate the normal background radiation. ${ }^{238} \mathrm{U},{ }^{232} \mathrm{Th}$, and ${ }^{40} \mathrm{~K}$ radionuclides that emit gamma radiations are carried to soil through the stream and rain [6] which considerably influences earthly gamma radiation elevations. Soil radioactivity is moreover, affected from human-made activities like nuclear weapons, tests and accidents which lead to the creation of fission products $\left({ }^{137} \mathrm{Cs}\right.$ and $\left.{ }^{90} \mathrm{Sr}\right)$ [7]. The existence of these radioactive isotopes at levels higher than the accepted rates $(35,35,14.8,400 \mathrm{~Bq} / \mathrm{kg}$ for ${ }^{238} \mathrm{U},{ }^{232} \mathrm{Th},{ }^{137} \mathrm{Cs}$ and ${ }^{40} \mathrm{~K}$ respectively) led 
towards the creation of cancers and birth defects $[8,9]$.

Measuring the radionuclides activity in bentonite is one of the significant studies, since this material is used widely and in direct contact with human skin which may pose a high levels of risks. There are no prior studies regarding the measurements of the radionuclide activities in Bentonite. This work was conducted to evaluate the activity concentrations of radionuclides in Bentonite collected from western Iraq (Tar-Alnajaf) and the radiation hazard indices due to the dealing with Bentonite mud which may include high levels of radiation that may pose cancer.

\section{Materials and Methods}

The bentonite samples were collected from Tar Al-Najaf on July 2017. Tar Al-Najaf is a cliff in Al Najaf city, located at the west of Iraq Fig.(1). Five samples of bentonite stones were collected and weighted as $1 \mathrm{~kg}$ each. Stones samples were left to dry for 10 days then it was crushed using stainless steel grade mill, sieved with 2-mm mesh, weighted and left for 1 month in coded marinelli beakers.

After measuring the gamma spectrum in gamma laboratory at department of physic, college of education for pure science, Ibn-Al-Haitham, Baghdad University, Baghdad (Iraq), the radionuclides activity concentration were calculate using high purity germanium HPGe detector.

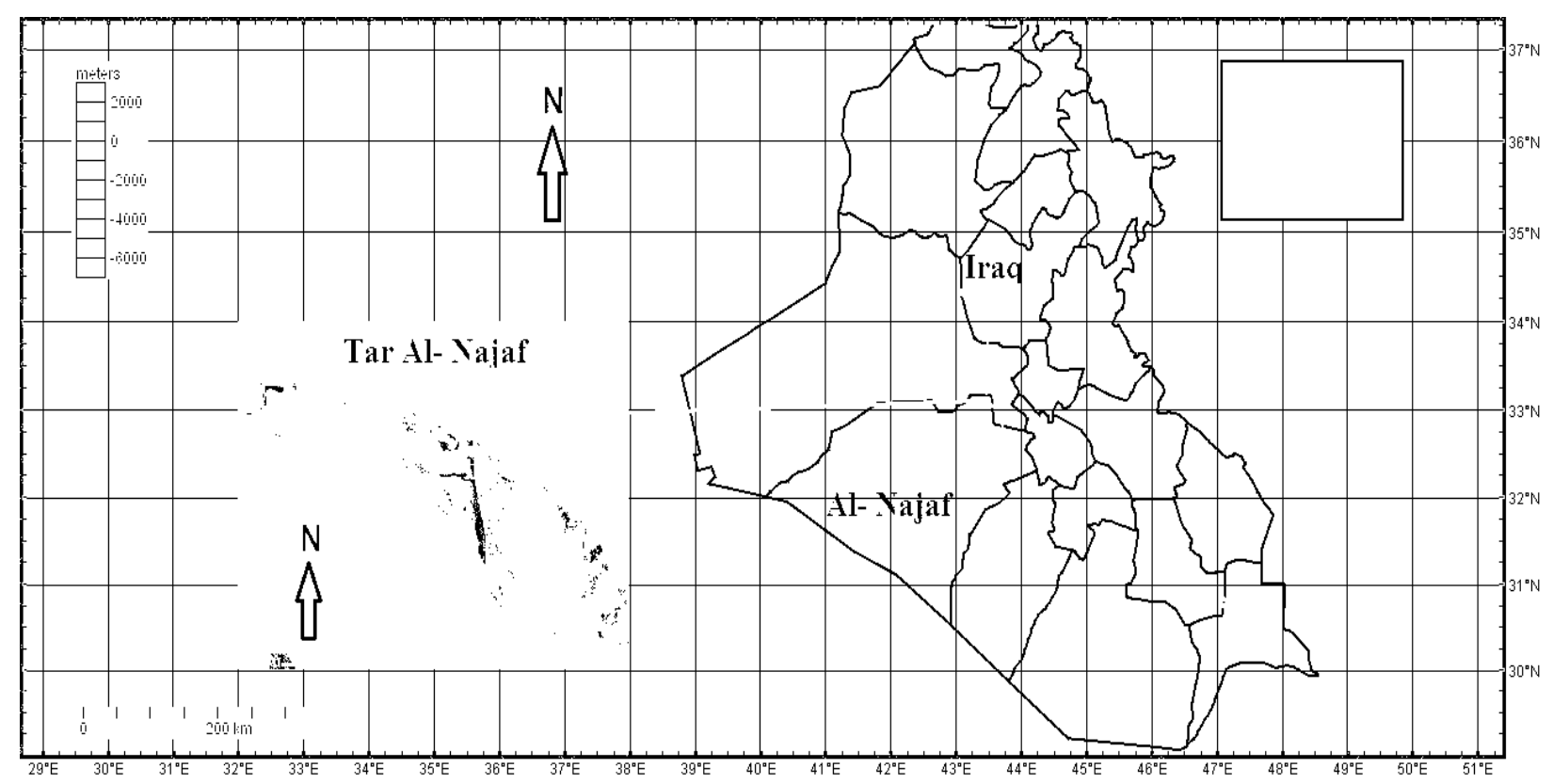

Fig.(1): Location of bentonite samples in this study at Al-Najaf cliff in Iraq map.

HPGe detector operating with Genie 2000 Canberra software was used to estimate the activity for whole samples. The detector was protected with $\mathrm{Pb}$ cover to prevent environmental gamma photons from reaching it to get correct evaluations. Also, the background correction was evaluated and found to be 1080 counts in $0.5 \mathrm{~h}$ and 2400 counts in $1 \mathrm{~h}$, these corrections were added to correct the gamma-ray peak's area with energies 238.6, 295.2, 351.9, 509.932, 583.2, 609.3, 661.6, 911.2, $1460.8 \mathrm{keV}$.

Fig.(2) indicates the efficiency calibration plotted against energy that performed using different energy peaks to cover the energy range from 60 up to $1600 \mathrm{keV}$. The efficiency calibration formula was fitted using the least square method and given by,

efficiency $(\%)=(0.16548 \pm 0.0238)+$

$(2.2268 \pm 0.796) \cdot e^{-(0.004072 \pm 0.000941) \cdot E}+$ $(8.3653 \pm 15.1) \cdot e^{-(0.021269 \pm 0.0191) \cdot E}$ 


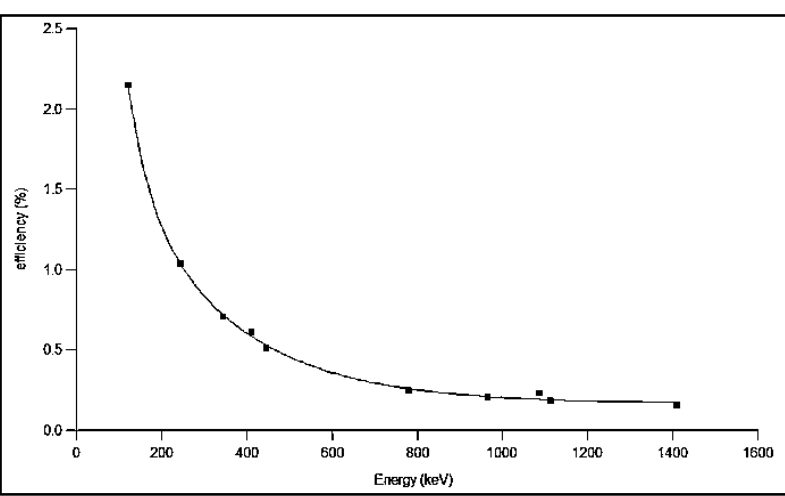

Fig.(2): Efficiency calibration curve of HPGe detector.

The radionuclide activity concentrations were estimated using the following expression [10],

$$
A=\frac{N_{D}}{T_{C} \cdot \eta(E) \cdot p \cdot m}
$$

where $N_{D}$ is the total counts of gamma-ray at energy $\mathrm{E}, T_{c}$ is the counting time in the sample, $\eta(E)$ is the efficiency of specific gamma-ray, $p$ is the gamma-ray yield, and $m$ is the mass of the sample in $\mathrm{kg}$.

Table (1)

Specific activity concentrations for the collected five samples from the main bentonite distribution markets.

\begin{tabular}{|c|c|c|c|c|c|c|c|c|}
\hline \multirow{3}{*}{$\begin{array}{c}\text { Radio-active } \\
\text { series }\end{array}$} & & \multirow{3}{*}{ E keV } & \multicolumn{5}{|c|}{ Samples number } & \multirow{3}{*}{$\begin{array}{c}\text { mean } \\
(B q / k g)\end{array}$} \\
\hline & & & 1 & 2 & 3 & 4 & 5 & \\
\hline & & & \multicolumn{5}{|c|}{ Specific activity concentrations (Bq/kg) } & \\
\hline & $\overline{40} \mathrm{~K}$ & $\overline{1460.8}$ & 251.27 & 183.16 & 122.78 & $\overline{188.01}$ & 62.33 & 161.51 \\
\hline & ${ }^{137} \mathrm{Cs}$ & 661.6 & 2.49 & 3.54 & 0.00 & 2.95 & 0.00 & 1.80 \\
\hline \multirow[t]{3}{*}{${ }^{232} \mathrm{Th}$} & ${ }^{212} \mathrm{~Pb}$ & 238.6 & 5.30 & 13.81 & 6.64 & 8.00 & 8.74 & 8.50 \\
\hline & ${ }^{208} \mathrm{Tl}$ & 583.2 & 2.06 & 3.45 & 3.33 & 0.55 & 0.90 & 2.06 \\
\hline & ${ }^{228} \mathrm{Ac}$ & 911.2 & 5.71 & 6.36 & 1.84 & 11.07 & 13.73 & 7.74 \\
\hline \multirow[t]{3}{*}{${ }^{238} \mathrm{U}$} & ${ }^{214} \mathrm{~Pb}$ & 295.2 & 5.66 & 6.42 & 2.68 & 5.58 & 10.87 & 6.24 \\
\hline & ${ }^{214} \mathrm{~Pb}$ & 351.9 & 6.15 & 3.38 & 4.48 & 10.50 & 0.14 & 4.93 \\
\hline & ${ }^{214} \mathrm{Bi}$ & 609.3 & 9.81 & 10.59 & 6.35 & 5.26 & 0.44 & 6.49 \\
\hline
\end{tabular}

The average activity concentration of ${ }^{232} \mathrm{Th}$ was measured from the mean peak energies of $238.6 \mathrm{keV}$ for ${ }^{212} \mathrm{~Pb}, 583.2 \mathrm{keV}$ for ${ }^{208} \mathrm{Tl}$ and $911.2 \mathrm{keV}$ for ${ }^{228} \mathrm{Ac}$. Similarly, the average activity concentration of ${ }^{238} \mathrm{U}$ was measured from the mean peak energies of $295.2 \mathrm{keV}$ for ${ }^{214} \mathrm{~Pb}$ and $351.9 \mathrm{keV}$ for ${ }^{214} \mathrm{~Pb}$ and $609.3 \mathrm{keV}$ for ${ }^{214} \mathrm{Bi}$ [11]. The activity concentration of ${ }^{40} \mathrm{~K}$ and ${ }^{137} \mathrm{Cs}$ was determined from the energies of 1460.8, and $661.6 \mathrm{keV}$ respectively. The activity concentration of

\section{Results and Discussions}

The activity concentrations of natural radionuclides ${ }^{214} \mathrm{~Pb},{ }^{208} \mathrm{Tl},{ }^{228} \mathrm{Ac},{ }^{214} \mathrm{~Pb},{ }^{214} \mathrm{Bi}$, ${ }^{137} \mathrm{Cs}$ and ${ }^{40} \mathrm{~K}$ in overall bentonite mud samples have been measured using high purity germanium gamma ray detector. The numerical results for all the activities and its mean values in $\mathrm{Bq} / \mathrm{kg}$ are listed in Table (1). 
Table (2)

Specific activity concentrations for ${ }^{40} \mathrm{~K},{ }^{137} \mathrm{Cs}$, ${ }^{232} \mathrm{Th}$, and ${ }^{238} \mathrm{U}$ in bentonite soil samples collected from the main Iraqi markets.

\begin{tabular}{|c|c|c|c|c|c|c|}
\hline \multirow{2}{*}{$\begin{array}{l}\text { Sample } \\
\text { No. }\end{array}$} & \multicolumn{5}{|c|}{$\begin{array}{c}\text { Specific activity } \\
\text { concentrations in }(B q / k g)\end{array}$} & \multirow{2}{*}{$\begin{array}{c}\text { Mean } \\
(\text { Bq/kg })\end{array}$} \\
\hline & 1 & 2 & 3 & 4 & 5 & \\
\hline${ }^{40} \mathrm{~K}$ & 251 & $\begin{array}{ll}183 \\
\end{array}$ & 123 & 7188 & 623 & 162 \\
\hline${ }^{137} \mathrm{Cs}$ & 2.49 & 3.54 & 0.00 & 2.95 & 0.00 & 1.80 \\
\hline$\overline{232} \mathrm{Th}$ & 4.36 & $\overline{c 7.87}$ & 3.94 & $\overline{c 6.54}$ & $\overline{l 7.79}$ & $\begin{array}{c}6.10 \\
\end{array}$ \\
\hline$\overline{238} \mathrm{U}$ & 7.21 & 26.80 & 44.50 & 7.11 & 3.82 & $\begin{array}{l}5.89 \\
\end{array}$ \\
\hline
\end{tabular}

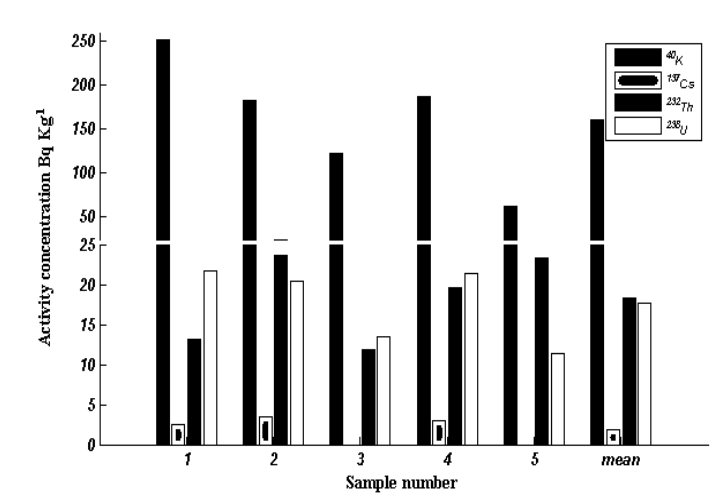

Fig.(3): Specific activity concentrations and its mean values for ${ }^{40} \mathrm{~K},{ }^{137} \mathrm{Cs},{ }^{232} \mathrm{Th}$ and ${ }^{238} \mathrm{U}$ in the five bentonite samples collected from the main distribution markets in Iraq.

The activity concentrations for the whole samples were very low when comparing with the worldwide activity concentrations according to the United Nations Scientific Committee on the Effects of Atomic Radiation (UNSCEAR) reports of ${ }^{238} \mathrm{U},{ }^{232} \mathrm{Th}$ and ${ }^{40} \mathrm{~K}$ concentrations in soil are $(35,30$ and $400 \mathrm{~Bq} / \mathrm{kg}$ ) respectively [8]. In all samples, the mean activity concentration is of the arrangement ${ }^{232} \mathrm{Th}<{ }^{238} \mathrm{U}<{ }^{40} \mathrm{~K}$. In addition to the previously recorded activities, ${ }^{137} \mathrm{Cs}$ activities of $2.49,3.54$, and $2.95 \mathrm{~Bq} / \mathrm{kg}$ were recorded in samples $1,2,4$. Cesium-137 in the environments does not created naturally, but it came from several sources where the most important source is the nuclear weapons.

The total air absorbed dose rate results from the mean activity concentration of ${ }^{238} \mathrm{U}$, ${ }^{232} \mathrm{Th}$ and ${ }^{40} \mathrm{~K}$ has been calculated using the following expression utilizing the factors $0.462,0.604$ and 0.042 for ${ }^{238} \mathrm{U},{ }^{232} \mathrm{Th}$ and ${ }^{40} \mathrm{~K}$ respectively $[12,13]$,

$$
D\left(n G y h^{-1}\right)=0.462 A_{U}+0.604 A_{T h}+0.042 A_{K}
$$

Also, the annual effective dose $D_{\text {eff }}$ has been measured using outdoor occupancy factor (OF), where it is $20 \%$ of 8760 hours per year or 0.2 of 8760 , and the conversion coefficient from absorbed dose in air to an effective dose of $0.7[12,8]$. The annual effective dose $D_{e f f}$ was estimated using the following expression $[8,14]$,

$D_{e f f}(S v)=D\left(n G y h^{-1}\right) \times 24 \times 365 h \times 0.7 \times 0.2$

Estimation of the $\gamma$-ray radiation hazards of soil to individuals due to the existence of ${ }^{238} \mathrm{U}$, ${ }^{232} \mathrm{Th}$, and ${ }^{40} \mathrm{~K}$ is very significant. Radium equivalent activity $R a_{e q}$ is one of the important radiation hazard indices that widely used to estimate the consistency of radiation exposure. If $R a_{e q}$ passes $370 \mathrm{~Bq} / \mathrm{Kg}$, this may raise radiation hazards. In this work, $R a_{e q}$ was determined in $\mathrm{Bq} / \mathrm{kg}$ using the following expression suggested by Beretka and Mathew [15],

$R a_{e q}=A_{U}+1.43 A_{T h}++0.077 A_{K}$

Another essential criterion used to evaluate the level of gamma radiation is defined by the external hazard index $\left(\mathrm{H}_{\mathrm{ex}}\right)$, which defined as follows [15, 16, 17],

$H_{e x}=\frac{A_{U}}{370}+\frac{A_{t h}}{259}+\frac{A_{K}}{4810}$

The measured values of activity concentrations can be used to extend the evaluations, and estimate the excess lifetime cancer risk (ELCR), to predict the risk that human being might infect cancer due to exposing to cancer-causing materials for extended long time $[14,18,19]$. The total ELCR was calculated using the estimated annual effective dose, and given by [20],

$E L C R=D_{\text {eff }} \times D_{L} \times R_{F}$

where, $D_{L}$ is the duration of life, and was assumed to be 66 years. $R_{F}$ is fatal risk factor per Sievert, which equals to $0.05 S v^{-1}$ for the public [21].

The total air absorbed dose rate, the annual effective dose, the radium equivalent activity, the external hazard index, and the excess lifetime cancer risk that calculated in the five samples were listed in Table (3). 
Table (3)

The total air absorbed dose rate, the annual effective dose, the radium equivalent activity, the external hazard index, and the excess lifetime cancer risk, in addition to its mean values in the five bentonite samples.

\begin{tabular}{||c||c|c|c|c|c||c||}
\hline \multicolumn{1}{|c||}{} & \multicolumn{5}{c||}{ Sample numbers } & \multirow{2}{*}{ mean } \\
\cline { 2 - 6 } & $\mathbf{1}$ & $\mathbf{2}$ & $\mathbf{3}$ & $\mathbf{4}$ & $\mathbf{5}$ & \\
\hline \hline $\mathbf{D}(\mathbf{n G y} / \mathbf{h})$ & $1.65 \mathrm{E}+01$ & $1.56 \mathrm{E}+01$ & 9.62 & $1.51 \mathrm{E}+01$ & 9.09 & $1.32 \mathrm{E}+01$ \\
\hline \hline $\mathbf{D}_{\text {eff }}(\mathbf{S v})$ & $2.03 \mathrm{E}-05$ & $1.91 \mathrm{E}-05$ & $1.18 \mathrm{E}-05$ & $1.86 \mathrm{E}-05$ & $1.11 \mathrm{E}-05$ & $1.62 \mathrm{E}-05$ \\
\hline $\mathbf{R a}_{\mathrm{eq}}(\mathbf{B q} / \mathbf{k g})$ & $3.28 \mathrm{E}+01$ & $3.22 \mathrm{E}+01$ & $1.96 \mathrm{E}+01$ & $3.09 \mathrm{E}+01$ & $1.98 \mathrm{E}+01$ & $2.70 \mathrm{E}+01$ \\
\hline $\mathbf{H}_{\mathbf{e x}}$ & $8.85 \mathrm{E}-02$ & $8.68 \mathrm{E}-02$ & $5.29 \mathrm{E}-02$ & $8.36 \mathrm{E}-02$ & $5.34 \mathrm{E}-02$ & $7.30 \mathrm{E}-02$ \\
\hline \hline $\mathbf{E L C R}$ & $6.68 \mathrm{E}-05$ & $6.31 \mathrm{E}-05$ & $3.89 \mathrm{E}-05$ & $6.12 \mathrm{E}-05$ & $3.68 \mathrm{E}-05$ & $5.34 \mathrm{E}-05$ \\
\hline
\end{tabular}

In this work, the total air absorbed dose rate $\mathrm{D}$ at $1 \mathrm{~m}$ over the ground was calculated for external exposure only, and not internally, since we assumed that the collected bentonite from the markets was not used in buildings, for this, $D$ for internal exposure is unimportant. $\mathrm{D}$ due to gamma radiation generated from ${ }^{238} \mathrm{U},{ }^{232} \mathrm{Th}$, and ${ }^{40} \mathrm{~K}$ was found to be ranging from 9.62 to 16.5 with an average of $13.2 \mathrm{nGy} / \mathrm{h}$. D values are less than the world's mean value of $59 \mathrm{nGy} / \mathrm{h}$ [8]. These values are considered to be minor, and do not constitute a danger to those dealing with it, the soil is considered intact, and does not pose any risk at $1 \mathrm{~m}$ above the ground from gamma radiation when dealing with it.

The annual effective dose $D_{\text {eff }}$ was found to be ranging from $1.11 \mathrm{E}-05$ to $2.03 \mathrm{E}-05$ with a mean value of $1.62 \mathrm{E}-05 \mathrm{~Sv}$. These values are low comparing to the world average value of 7E-05 Sv [8]. The results indicated that there is no risk of developing fatal cancer in the body due to utilizing bentonite or being near it.

The radium equivalent activities $\left(\mathrm{Ra}_{\mathrm{eq}}\right)$ was calculated utilizing the formula given in equation (5). The activity limits in terms of $\mathrm{Ra}_{\mathrm{eq}}$ is $350 \mathrm{~Bq} / \mathrm{kg}$ [14], for the allowed unharmed use of soil products. The $\mathrm{Ra}_{\mathrm{eq}}$ activity values were ranging from $1.96 \mathrm{E}+01$ to $3.28 \mathrm{E}+01$ with an average of $2.70 \mathrm{E}+01 \mathrm{~Bq} / \mathrm{kg}$ which is less than the global limit by (UNSCEAR) [8] as shown in Table (3). The outcome measurements of external radiation hazard index are shown in Table (3), in the bentonite samples, the external hazard index was found to be ranging from $5.29 \mathrm{E}-02$ to $8.85 \mathrm{E}-02$ with an average of 7.30E-02. The hazard index of all site samples was found to be less than the allowed level (Unity) [22]
Table (3). The mean value of ELCR for all samples (5.34E-05) is lower than the world mean value (1.45E-3) [15]. It may be noted that ELCR for Iraqi bentonite is less than the world's average of 1.45 [15]. According to these outcomes, the risk of cancer has no significant effect, and is found to be negligible. Fig.(4) indicates the ELCR values in the five samples, and the mean values obtained in this work.

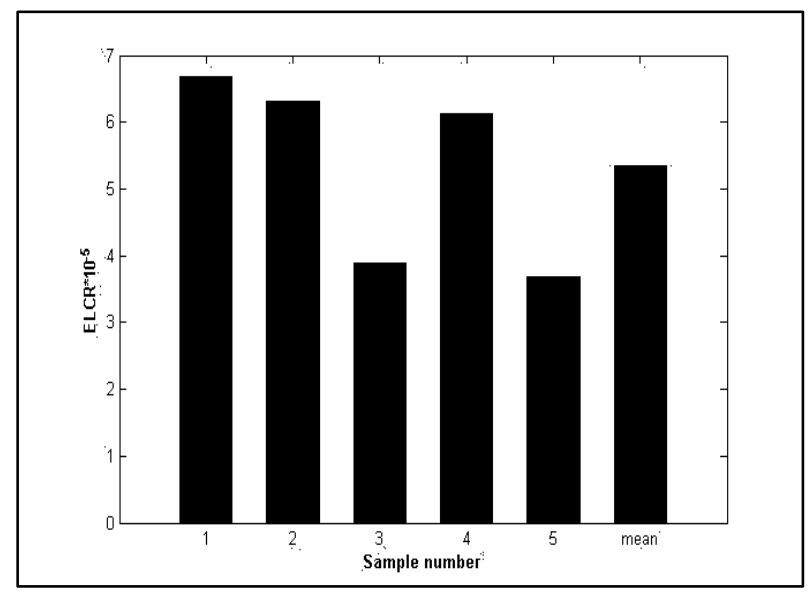

Fig.(4): The excess lifetime cancer risk for the five samples of bentonite collected from the main Iraqi markets.

\section{Conclusions}

The mean specific activities of bentonite soil samples collected from the main distribution markets in Baghdad, the capital of Iraq were very low, and within world's normal limits. The estimated total air absorbed dose rate, the annual effective dose, the radium equivalent activity, the external hazard index, and the excess lifetime cancer risk were found to be lower than recommended safe limit values. This indicated that the inhabitants in the area where bentonite soil was collected 
from, and dealers with this kind of soil are safe, and not expose to high levels of radiation. This mean that the bentonite soil is safe, and does not lead to radiation risks.

\section{References}

[1] Parker S. P., "McGraw-Hill encyclopedia of the geological sciences", 2nd ed., New York, McGraw-Hill, 32-33, 69-72, 400-401, 1988.

[2] Grim, R. E., "Clay mineralogy", 2nd ed., New York, McGraw-Hill, 596, 1968.

[3] Patterson, S. H., Murray, H. H., "Clays. In: Lefond SI ed. Industrial minerals and rocks", 5th ed., New York, American Institute of Mining, Metallurgical, and Petroleum Engineers, 585-651, 1983.

[4] Zoltan, A., Richard, B., "Environmental Health Criteria 231: Bentonite, kaolin, and selected clay minerals", World Health Organization. A report Published under the joint sponsorship of the United Nations Environment Programme, the International Labour Organization, and the World Health Organization, and produced within the framework of the Inter-Organization Programme for the Sound Management of Chemicals, Geneva, 2005.

[5] IAEA (International Atomic Energy Agency), "Radiation Safety standard series", Regulation for the safe transport of radioactive material. IAEA Division of Public Information, 96-00725 IAEA/PI/A47E, Vienna, Austria, 1996.

[6] NCRP (National Council on Radiation Protection and Measurement), "Natural Background Radiation in the United States", Soil Radioactivity No.45, Washington D. C., 1975.

[7] IAEA (International Atomic Energy Agency), "Radioactive Particles in the Environment: Sources, Particle Characterization and Analytical Techniques", IAEA-TECDOC1663, (ISBN: 978-92-0-119010-9), Vienna, Austria, 2011.

[8] UNSCEAR (United Nations Scientific Committee on the Effects of Atomic Radiation), "Sources and effects of ionizing radiations", A report on the Effects of Atomic Radiation to the General Assembly with Scientific Annexes, Annex B, United Nations, New York, 2000.
[9] Taskin, H., Karavus, M., Ay, P., Topuzoglu, A., Hindiroglu, S., Karahan, G., "Radionuclide concentrations in soil and lifetime cancer risk due to the gamma radioactivity in Kirklareli Turkey", J. Environ. Radioact. 100, 49-53, 2009.

[10] Mohammed, R. S., Ahmed, R. S., "Estimation of excess lifetime cancer risk and radiation hazard indices in southern Iraq", Environ. Earth. Sci. 76, 303, 2017.

[11] Alnour, I. A., Ibrahim, N., Hossain, I., "Concentrations of ${ }^{214} \mathrm{~Pb},{ }^{214} \mathrm{Bi}$ in ${ }^{238} \mathrm{U}$ series and ${ }^{208} \mathrm{Tl},{ }^{228} \mathrm{Ac}$ in ${ }^{232} \mathrm{Th}$ series in granite rock in (Kadugli) Sudan", Indian J. Pure. Appl. Phys. 50, 285-288, 2012.

[12] United Nations Scientific Committee on the Effects of Atomic Radiation (UNSCEAR)," Sources and Effects of Ionizing Radiation", Report to the General Assembly, with scientific Annexes, United Nations, New York, 1993.

[13] Beck, H. L., DeCompo, J., Gologak, C., "Ge(Li) and Nai(Tl) gamma ray Spectrometry", Health and Safety Laboratory AEC, New York, Report Has 1285, 1972.

[14] Beretka, J., Mathew, P. J., "Natural radioactivity of Australian building materials, industrial wastes and byproducts", Health Phys. 48, 87-95, 1985.

[15] Qureshi, A. A., Tariq, S., Din, K. U., Manzoor, S., Calligaris, C., Waheed, A., "Evaluation of excessive lifetime cancer risk due to natural radioactivity in the rivers sediments of Northern Pakistan", J. Radiat. Res. Appl. Sci. 7, 438-447, 2014.

[16] OECD - Organization for Economic Cooperation and Development, "Exposure to radiation from the natural radioactivity in building materials", (Report by a group of experts), Paris, France, Nuclear Energy Agency, 1979.

[17] Alam, M. N., Miah, M. M. H., Chowdhury, M. I., Kamal, M., Ghose, S., Islam, M. N., Mustafa, M. N., Miah, M. S. R., "Radiation dose estimation from radioactivity analysis of lime and cement used in Bangladesh", J. Environ. Radioact. 42, 77-85, 1999.

[18] Jallad, K. N., "Radiation hazard indices and excess lifetime cancer risk in sand from the northern and eastern regions of 
Kuwait”, Environ. Earth. Sci. 75, 156, 2016.

[19] Dizman, S., Görür, F. K., Keser, R., "Determination of radioactivity levels of soil samples and the excess of lifetime cancer risk in Rize province, Turkey", Int. J. Radiat. Res. 14(3), 237-244, 2016.

[20] Ramasamy, V., Suresh, G., Meenakshisundaram, V., Gajendran, V., "Evaluation of natural radionuclide content in river sediments and excess lifetime cancer risk due to gamma radioactivity", Res. J. Env. Earth. Sci. 1, 6-10, 2009.

[21] Burnham, J. U., "Dose limits and risks", In: Burnham JU (ed) radiation protection, The International Commission on Radiological Protection (ICRP) Publication 60, Brunswick, Canada, 109-128, 1991.

[22] Orgun, Y., Altinsoy, N., Sahin, S.Y., Gungor, Y., Gultekin, A.H., Karaham, G., et al., "Natural and anthropogenic radionuclides in rocks and beach sands from Ezine region (canakkale), Western Anatolia, Turkey", Àppl. Radiat. Isotopes. 65, 739-747, 2007. 